\title{
Effects of Water Stress on Botryosphaeria Blight of Pistachio Caused by Botryosphaeria dothidea
}

\author{
Zhonghua Ma, David P. Morgan, and Themis J. Michailides, Department of Plant Pathology, University of Cali- \\ fornia, Kearney Agriculture Center, 9240 S. Riverbend Avenue, Parlier 93648
}

\begin{abstract}
Ma, Z., Morgan, D. P., and Michailides, T. J. 2001. Effects of water stress on Botryosphaeria blight of pistachio caused by Botryosphaeria dothidea. Plant Dis. 85:745-749.

The effects of water potential $(\psi)$ on spore germination, germ tube elongation, mycelial growth of Botryosphaeria dothidea, and development of Botryosphaeria blight of pistachio caused by this fungus were studied in the laboratory and greenhouse. In laboratory tests, spore germination, germ tube elongation, and mycelial growth of $B$. dothidea increased as $\psi$ decreased from 0 to $-2.0 \mathrm{MPa}$ and declined as $\psi$ decreased below $-2.0 \mathrm{MPa}$. Water stress $(\psi<-0.260 \mathrm{MPa})$ increased the severity of Botryosphaeria blight on young detached pistachio leaves. In greenhouse inoculation experiments, drought-stressed 2-year-old pistachio trees (leaf $\psi<-0.635 \mathrm{MPa}$ ) developed more severe Botryosphaeria blight disease than the nonstressed trees $(\psi>-0.485$ MPa) in both 1999 and 2000 experiments. In a similar experiment using 1-year-old potted pistachio trees in 2000, withholding water treatments did not cause enough drought stress in pistachio leaves $(\psi>-0.584 \mathrm{MPa})$ and did not result in higher disease than the nonstressed trees $(\psi$ $=-0.466 \mathrm{MPa}$ ). The correlation coefficient between $\psi$ and disease index for 1999 experiments was 0.954 , and for 2000 experiments I and II was 0.981 and 0.939 , respectively. These results indicate that drought stress can be a major predisposing factor of pistachio to infection by $B$. dothidea. Results from this study can be used to better understand the disease outbreaks in California pistachio orchards and to develop integrated management strategies by adjusting irrigation.
\end{abstract}

The California pistachio (Pistacia vera L.) industry presently comprises over 30,000 bearing hectares producing an annual crop valued at over $\$ 160$ million (4). As the growing area of pistachio in California has expanded, fungal diseases have become a major threat to the industry, causing significant losses. Botryosphaeria panicle and shoot blight of pistachio, caused by Botryosphaeria dothidea (Moug.:Fr.) Ces. \& De Not., is a devastating disease of pistachio trees in California. The disease was first recorded in the summer of 1984 from a commercial orchard in Butte County and was subsequently identified in other orchards in the Sacramento Valley (22). In 1995, the disease was detected in pistachio plantings in the San Joaquin Valley (21), and in 1998, B. dothidea was recovered from the southernmost part of Kern County (23), suggesting that the disease has spread throughout the pistachio-growing areas in California. Disease outbreaks were initially more severe in orchards located in the northern Sacramento Valley, where pistachios were irrigated mainly by high-angled sprinklers $(18,19)$, but subsequently, the disease has

Corresponding author: T. J. Michailides

E-mail: themis@uckac.edu

Accepted for publication 22 March 2001.

Publication no. D-2001-0511-01R

(C) 2001 The American Phytopathological Society become a severe threat to all irrigated pistachio plantings throughout the state (21). The fungus attacks and kills fruit clusters, and yield losses of 40 to $100 \%$ have been reported in some orchards (17). Due to the rapid spread and the destructive nature of this pathogen throughout California, Botryosphaeria panicle and shoot blight is now considered the single greatest threat to the California pistachio industry.

Although B. dothidea has been found on a wide range of host species, it can cause serious damage only to those host plants that are weakened or under environment stress (30). The most common stresses associated with predisposition in woody plants are drought and freezing (29). Drought stress was identified as the major predisposing factor involved in attack of apple (12), sweetgum (25), European white birch (7), and peach (27) by B. dothidea. During 1990 to 1995 , there was a 5-year drought in California that coincided with sudden outbreaks of Botryosphaeria blight in California pistachio orchards. Based on preliminary field observations, we hypothesized that drought might serve as a major predisposing stress factor of pistachio to infection by $B$. dothidea. However, there are no reports in the literature demonstrating a relationship between drought stress and Botryosphaeria blight of pistachio. Currently, there is no effective control for Botryosphaeria blight, although there has been some recent success with sterol demethylation inhibitor and stro- bilurin fungicides (20). An understanding of the effects of water stress on the development of this disease in pistachio may be used for developing integrated disease management strategies by a combination of adjusting irrigation and other cultural and chemical controls.

Numerous reports deal with the effects of water potential $(\psi)$ on growth of various plant pathogens (8), but similar reports on $B$. dothidea are lacking. Effects of $\psi$ on fungal growth in culture are often studied by varying the osmotic potential of agar media by the addition of solutes (osmotica), usually $\mathrm{KCl}, \mathrm{NaCl}$, or sucrose (32). Regardless of media or osmotica used to control $\psi$, generally there are four typical relationships between $\psi$ and growth of fungi (8), and most fungi show a decrease in radial mycelial growth with decreasing $\psi$ in media (32).

The objectives of this study were to determine (i) the effects of $\psi$ on spore germination, germ tube elongation, and mycelium growth of $B$. dothidea; (ii) the effects of $\psi$ on Botryosphaeria blight on detached pistachio leaves; and (iii) the effects of drought stress on Botryosphaeria blight of pistachio in a greenhouse.

\section{MATERIALS AND METHODS}

Isolate and inoculum production. The isolate of $B$. dothidea $15 \mathrm{~A}$, obtained from a diseased commercial pistachio orchard in 1998 from Glenn County, CA, was used throughout this study. The stock culture of isolate $15 \mathrm{~A}$ was stored in grade 40 silica gel (Davison Chemical, Baltimore, MD) at $9^{\circ} \mathrm{C}$.

To prepare spore suspensions, mycelial plugs of isolate $15 \mathrm{~A}$ were transferred to autoclaved pistachio leaves placed on the surface of agar in petri dishes, each containing $5 \mathrm{ml}$ of acidified half-strength potato dextrose agar (PDA) (20 g of PDA, 10 $\mathrm{g}$ of agar, $2.5 \mathrm{ml}$ of $25 \%$ solution of lactic acid per liter). Pycnidia of $B$. dothidea developed on leaves after 2 weeks incubation at room temperature $\left(23 \pm 2^{\circ} \mathrm{C}\right)$. Petri dishes were flooded with sterile water, and the resulting spore suspension was then filtered through two layers of sterile cheesecloth. The spore concentrations were adjusted with a hemacytometer to 2,000 spores per milliliter for spore germination and germ tube elongation tests and 20,000 spores per milliliter for inoculations of pistachio trees in a greenhouse.

Effects of $\psi$ on spore germination and germ tube elongation. Each plastic petri 
dish (9 cm diameter) containing $20 \mathrm{ml}$ of $2 \%$ agar, amended with various concentrations of $\mathrm{KCl}$ or sucrose (28) to create different levels of $\psi$ from 0 to $-6 \mathrm{MPa}$, was spread with $100 \mu \mathrm{l}$ of the 2,000-spores per milliliter suspension. All dishes were sealed with Parafilm, placed in closed plastic containers, and incubated at $30^{\circ} \mathrm{C}$. There were three replicate dishes for each $\psi$ level created by $\mathrm{KCl}$ or sucrose. Rates of spore germination and lengths of germ tubes were assessed for 100 spores per petri dish after incubation for 4 and $8 \mathrm{~h}$, respectively. The experiment was performed twice, and data presented are the averages of the two experiments since there was no statistical difference $(P>$ $0.05)$ in the rates of spore germination and lengths of germ tubes between the experiments.

Effects of $\psi$ on mycelium growth. PDA was used as a basic medium. Various amounts of $\mathrm{KCl}$ or sucrose (28) were added to the media to create different $\psi$ levels ranging from -2 to $-18 \mathrm{MPa}$.

Mycelial plugs (5 $\mathrm{mm}$ diameter) were taken from the edge of 3-day-old colonies of $B$. dothidea grown on PDA medium and transferred to petri dishes, each containing $20 \mathrm{ml}$ of medium amended with $\mathrm{KCl}$ or sucrose (three replicate dishes for each $\psi$ level created by $\mathrm{KCl}$ or sucrose). All dishes were sealed with Parafilm and placed in closed plastic containers. After incubation at $30^{\circ} \mathrm{C}$ for 3 days in the dark, colony diameters in millimeters for each petri dish were measured in two perpendicular direc- tions. The experiment was performed twice, and results were averaged since there was no significant difference $(P>$ 0.05 ) in colony diameter of $B$. dothidea between the two experiments.

Effects of water stress on Botryosphaeria blight on detached pistachio leaves. The amounts of $\mathrm{KCl}$ needed for preparing the solutions with various $\psi$ levels from 0 to $-4 \mathrm{MPa}$ were calculated according to a previously published protocol (28). $\mathrm{KCl}$ was dissolved in deionized water using a magnetic stirrer before autoclaving.

In laboratory tests, fully expanded young pistachio leaves (collected from a fungicide-free orchard) were surface-sterilized in $0.05 \%$ sodium hypochlorite solution for $3 \mathrm{~min}$ and rinsed with sterilized water three times. Ten leaves were placed on a waxed screen in a closed plastic container $(32 \times$ $23.5 \times 10 \mathrm{~cm}$ ) containing $300 \mathrm{ml}$ of a $\mathrm{KCl}$ solution with $\psi=0,-1,-2,-3$, or $-4 \mathrm{MPa}$. Leaf petioles were placed into the solutions and incubated at $30^{\circ} \mathrm{C}$ for $24 \mathrm{~h}$ to allow equilibration of $\psi$ between solutions and leaves. There were 20 leaves for each treatment. Actual $\psi$ of each detached leaf was determined using a pressure bomb (Soilmoisture Equipment Corp., Santa Barbara, CA). Each treated leaf was wounded once with an inoculating needle in the center of the main rib vein and inoculated with a 3-mm-diameter mycelial plug taken from the edge of a 3-day-old colony. The lesion diameter for each leaf was recorded after 4 days of incubation at

Table 1. Analysis of variance for the effects of water potential $(\psi)$ on spore germination, germ tube elongation, mycelial growth of Botryosphaeria dothidea, and on the development of Botryosphaeria blight on detached pistachio leaves and potted pistachio trees caused by $B$. dothidea

\begin{tabular}{|c|c|c|c|c|}
\hline Response variable & Source & df & $F$ value & $P>F$ \\
\hline \multicolumn{5}{|c|}{ Spore germination (4 h) } \\
\hline & Chemical & 1 & 822.17 & $<0.0001$ \\
\hline & $\psi$ & 6 & $3,912.75$ & $<0.0001$ \\
\hline & $\psi \times$ chemical & 6 & 130.97 & $<0.0001$ \\
\hline \multicolumn{4}{|c|}{ Spore germination $(8 \mathrm{~h})$} & 0.0414 \\
\hline & $\psi$ & 6 & $4,578.52$ & $<0.0001$ \\
\hline & $\psi \times$ chemical & 6 & 3.41 & 0.0274 \\
\hline \multicolumn{5}{|c|}{ Germ tube elongation ( $4 \mathrm{~h}$ ) } \\
\hline & Chemical & 1 & $3,950.11$ & $<0.0001$ \\
\hline & $\psi$ & 6 & $4,236.87$ & $<0.0001$ \\
\hline & $\psi \times$ chemical & 6 & 735.74 & $<0.0001$ \\
\hline \multicolumn{5}{|c|}{ Germ tube elongation ( $8 \mathrm{~h}$ ) } \\
\hline & Chemical & 1 & 127.10 & $<0.0001$ \\
\hline & $\psi$ & 6 & $1,914.35$ & $<0.0001$ \\
\hline & $\psi \times$ chemical & 6 & 17.11 & $<0.0001$ \\
\hline \multicolumn{5}{|l|}{ Mycelial growth } \\
\hline & Chemical & 1 & $1,692.21$ & $<0.0001$ \\
\hline & $\psi$ & 6 & $5,626.75$ & $<0.0001$ \\
\hline & $\psi \times$ chemical & 6 & 344.89 & $<0.0001$ \\
\hline \multicolumn{5}{|l|}{ Lesion diameter on } \\
\hline $\mathrm{DI}^{\mathrm{z}}$ & $\begin{array}{l}\text { Days without water } \\
\text { (1999/Exp. I \& II) }\end{array}$ & 3 & 18.50 & 0.0083 \\
\hline DI & $\begin{array}{l}\text { Days without water } \\
\text { (2000/Exp. I) }\end{array}$ & 3 & 9.21 & 0.0011 \\
\hline DI & $\begin{array}{l}\text { Days without water } \\
\text { (2000/Exp. II) }\end{array}$ & 3 & 1.02 & 0.411 \\
\hline
\end{tabular}

${ }^{\mathrm{z}}$ Disease index was calculated using five severity categories ( 0 to 4$)$, with $0=$ leaves without lesions and $4=$ lesion area greater than three-fourths of leaf area. $30^{\circ} \mathrm{C}$. The experiment was performed twice. Analysis of variance, using the ANOVA procedure of SAS (Version 8.0, SAS Institute, Cary, NC) was conducted to determine the effect of $\psi$ on lesion diameters on detached pistachio leaves.

Effects of drought stress on Botryosphaeria blight of pistachio in a greenhouse. The pistachio cultivar Kerman, which is susceptible to Botryosphaeria blight, was selected for greenhouse experiments. Potted, 2-year-old trees were obtained from a pistachio nursery for experiments in 1999 and experiment I in 2000. One-year-old trees were used in experiment II in 2000. All trees were sprayed with a 20,000-spores per milliliter suspension of $B$. dothidea until a fine film of droplets was deposited uniformly on the leaves. To create favorable conditions for infection, each inoculated tree was covered with a plastic bag for $12 \mathrm{~h}$. Three different levels of water stress were established for each experiment by withholding water from five replicate trees for 5,8 , or 11 days after inoculation. Before irrigating the drought-stressed trees, the levels of $\psi$ in mature pistachio leaves ( 1 month after fully expanded) were measured for each water-stressed tree using the pressure bomb between 9:00 and 10:00 A.M. Each control tree without induced water stress was irrigated with 1 liter of water per day using drip irrigation. Disease severity was assessed 15 days after inoculation. The following system was used for severity assessment: $0=$ leaves without lesions, $1=$ lesion area less than one-fourth of the leaf area, $2=$ lesion area between one-fourth and one-half of the leaf area, $3=$ lesion area between one-half and three-fourths of the leaf area, and $4=$ lesion area greater than three-fourths of the leaf area. The disease index (DI) for each tree was calculated using the formula:

$$
D I=\left(\sum_{i=0}^{4} N_{i} * i\right) / \sum_{i=0}^{4} N_{i}
$$

where $i$ is severity ( 0 to 4 ) and $N_{i}$ is the number of leaves with the severity of $i$. Analysis of variance for DI of waterstressed pistachio trees affected by $\psi$ was conducted using the ANOVA procedure of SAS.

\section{RESULTS}

Spore germination and germ tube elongation. Spore germination and germ tube elongation of $B$. dothidea increased significantly (Table $1, P<0.0001$ ) as $\psi$ decreased from 0 to $-2.0 \mathrm{MPa}$ and declined as $\psi$ was further decreased. After incubation at $30^{\circ} \mathrm{C}$ for $4 \mathrm{~h}$, spores of $B$. dothidea germinated faster at $-3 \leq \psi \leq-1 \mathrm{MPa}$ than at $\psi=0 \mathrm{MPa}$ both on KCl- and sucroseamended agar. The maximum percentage of spore germination occurred at $-2 \leq \psi \leq$ $-1 \mathrm{MPa}$ on either $\mathrm{KCl}$ - or sucroseamended agar. Spores did not germinate at $\psi<-5 \mathrm{MPa}$ (Fig. 1). Spores germinated 
more rapidly on sucrose-amended agar than on KCl-amended agar at $-4 \leq \psi \leq-1$ MPa (Fig. 1). The interactions between the levels of $\psi$ and chemicals $(\mathrm{KCl}$ and sucrose) on spore germination of $B$. dothidea were significant (Table $1, P<0.0001$ ).

After incubation at $30^{\circ} \mathrm{C}$ for $8 \mathrm{~h}, 100 \%$ of spores germinated on $\mathrm{KCl}$ - or sucroseamended agar at $-4 \leq \psi \leq 0 \mathrm{MPa}$. However, only 39 and $34 \%$ of spores germinated at $\psi=-6 \mathrm{MPa}$ on the $\mathrm{KCl}-$ and sucrose-amended agar, respectively.

Similarly to spore germination, germ tubes of $B$. dothidea grew faster at $-2 \leq \psi$ $\leq-1 \mathrm{MPa}$ on either $\mathrm{KCl}$ - or sucroseamended agar than at $\psi=0 \mathrm{MPa}$ after incubation at $30^{\circ} \mathrm{C}$ for 4 (Fig. 2A) or $8 \mathrm{~h}$ (Fig. 2B). Germ tube length increased significantly (Table $1, P<0.0001$ ) as $\psi$ decreased from 0 to $-1 \mathrm{MPa}$ on either $\mathrm{KCl}$ or sucrose-amended agar, and the maximum germ tube length occurred at $-2 \leq \psi$

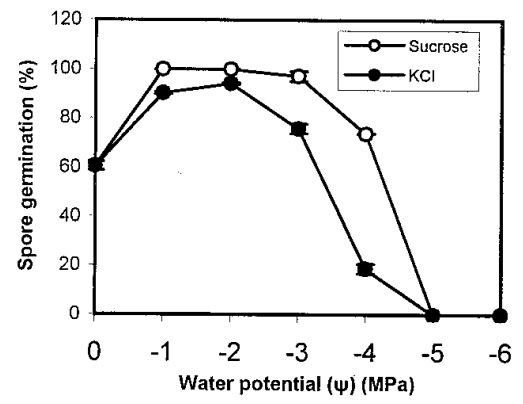

Fig. 1. Effects of water potential $(\psi)$ on spore germination of Botryosphaeria dothidea on sucrose- or $\mathrm{KCl}$-amended agar after incubation at $30^{\circ} \mathrm{C}$ for $4 \mathrm{~h}$. Bars denote standard errors.
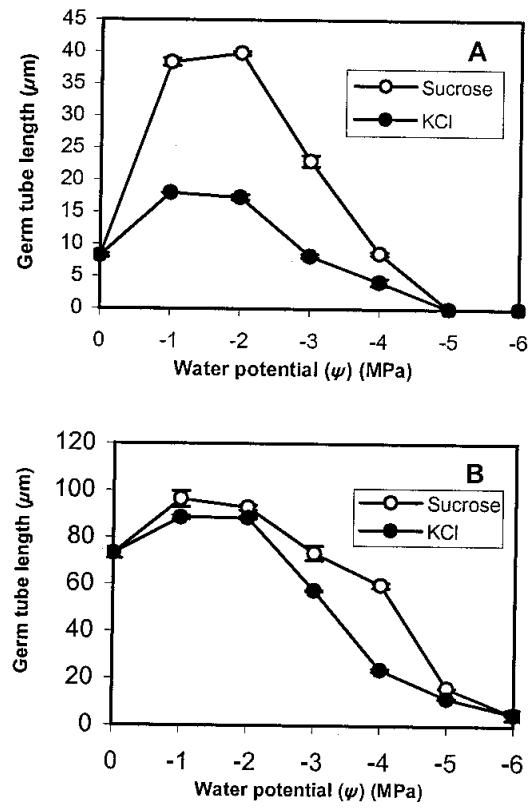

Fig. 2. Effects of water potential $(\psi)$ on germ tube elongation of Botryosphaeria dothidea on sucrose- or $\mathrm{KCl}$-amended agar after incubation at $30^{\circ} \mathrm{C}$ for $\mathbf{A}, 4 \mathrm{~h}$ and $\mathbf{B}, 8 \mathrm{~h}$. Bars denote standard errors. $\leq-1 \mathrm{MPa}$. Germ tube elongation, however, declined as $\psi$ further decreased. Germ tubes grew more rapidly on sucroseamended agar than on $\mathrm{KCl}$-amended agar (Fig. 2A). The interactions between $\psi$ and chemicals ( $\mathrm{KCl}$ and sucrose) on germ tube elongation were also significant (Table $1, P$ $<0.0001$ ).

Mycelial growth. After incubation at $30^{\circ} \mathrm{C}$ for 3 days, the radial growth of $B$. dothidea increased significantly (Table 1 , $P<0.0001)$ as $\psi$ decreased from -0.3 to $-2.0 \mathrm{MPa}$, and declined as $\psi$ further decreased (Fig. 3). Radial growth of $B$. dothidea on sucrose-amended media declined more slowly than on $\mathrm{KCl}$-amended media (Fig. 3). Optimum $\psi$ for mycelial growth of $B$. dothidea was at $-2 \mathrm{MPa}$ on either $\mathrm{KCl}-$ or sucrose-amended media. These results agreed with those found for spore germination and germ tube elongation. Mycelial growth of $B$. dothidea ceased at $\psi=-14 \mathrm{MPa}$ and $-18 \mathrm{MPa}$ on $\mathrm{KCl}-$ and sucrose-amended media, respectively, after 3 days of incubation at $30^{\circ} \mathrm{C}$.

Botryosphaeria blight on detached pistachio leaves. The $\psi$ in fresh young pistachio leaves was about $-0.274 \mathrm{MPa}$. After leaf petioles were placed into $\mathrm{KCl}$ solutions with various levels of $\psi$ for 1 day, values of $\psi$ in young pistachio leaves decreased as solution $\psi$ decreased (Table 2). All the detached leaves showed dehydration and wilting after the leaf petioles were placed into the $\mathrm{KCl}$ solution of $\psi=$ $-4 \mathrm{MPa}$ for 1 day.

After detached leaves were inoculated with mycelial plugs and incubated at $30^{\circ} \mathrm{C}$ for 4 days, lesion diameters of Botryosphaeria blight increased significantly (Ta-

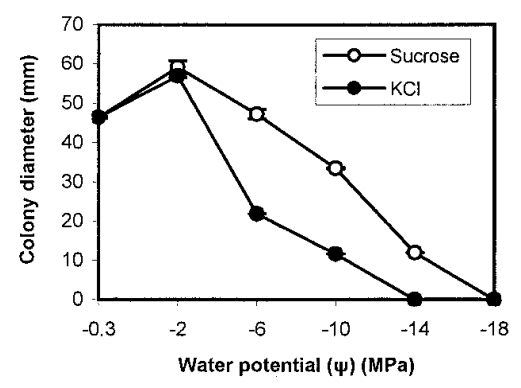

Fig. 3. Effects of water potential $(\psi)$ on the mycelial growth of Botryosphaeria dothidea on potato dextrose agar media amended with sucrose or $\mathrm{KCl}$. Bars denote standard errors. ble $1, P=0.0003)$ as $\psi$ of detached leaves decreased (Table 2). The lesion diameter on leaves having $\psi=-0.196 \mathrm{MPa}$ was $3.44 \mathrm{~cm}$ and increased by 27,51 , and $90 \%$ on leaves having $\psi=-0.260,-0.328$, and $-0.444 \mathrm{MPa}$, respectively.

Botryosphaeria blight of pistachio in the greenhouse. In the greenhouse, $\psi$ for mature leaves of potted pistachio trees decreased significantly after 8 days without water for both the 1999 and 2000 experiments (Table 3). In 1999, compared with the trees without water stress, values of $\psi$ of pistachio leaves decreased by 31 and $54 \%$ in the trees without water for 8 and 11 days, respectively. In a preliminary experiment, three of five 2-year-old potted pistachio trees showed irreversible wilt after 15 days without water. In 2000, the 1year-old trees in experiment II appeared more tolerant to withholding water than the 2-year-old trees in experiment I. Water potentials for the pistachio leaves in 1- and 2-year-old trees held without water for 8 days decreased by 18.03 and $48.72 \%$, respectively (Table 3 ).

Drought stress increased the severity of Botryosphaeria blight of pistachio. The correlation coefficient between DI and $\psi$ for the 1999 experiments was 0.954, and for 2000 experiments I and II was 0.981 and 0.939, respectively. In 1999, Botryosphaeria blight on pistachio leaves increased significantly (Table $1, P=0.0083$ ) as $\psi$ decreased (Table 3). DI for the trees without water for 5 and 8 days increased by 101 and $154 \%$ compared with trees without water stress, respectively. A similar trend was observed in 2000 experiment I, although the DI of trees without water for 11 days increased by $80.58 \%$ compared with the trees without water stress in this experiment (Table 3). For the 2000 experiment II, due to smaller decreases in $\psi$ of the water-stressed 1-year-old trees (Table $3)$, DIs for the water-stressed trees $(\psi \geq$ $-0.584 \mathrm{MPa})$ were not significantly different (Table $1, P=0.411$ ) from the DI of the trees without water stress $(\psi=-0.466$ $\mathrm{MPa})$.

\section{DISCUSSION}

Water potential $(\psi)$ is widely recognized as an important factor in the ecology and growth of plant-pathogenic fungi, and much has been done to elucidate the influence of $\psi$ upon mycelial growth (33). Re-

Table 2. Effects of water potential $(\psi)$ on Botryosphaeria blight on young detached pistachio leaves maintained in $\mathrm{KCl}$ solutions and inoculated with Botryosphaeria dothidea

\begin{tabular}{ccc}
\hline $\begin{array}{c}\psi \text { of KCl solution } \\
(-\mathbf{M P a})\end{array}$ & $\begin{array}{c}\psi \text { of young detached leaves } \\
(-\mathbf{M P a})\end{array}$ & $\begin{array}{c}\text { Lesion diameter } \\
(\mathbf{c m})\end{array}$ \\
\hline 0 & $0.196^{\mathrm{y}} \mathrm{d}^{\mathrm{z}}$ & $3.44^{\mathrm{y}} \mathrm{d}^{\mathrm{z}}$ \\
1 & $0.260 \mathrm{c}$ & $4.37 \mathrm{c}$ \\
2 & $0.328 \mathrm{~b}$ & $5.20 \mathrm{~b}$ \\
3 & $0.444 \mathrm{a}$ & $6.54 \mathrm{a}$ \\
\hline
\end{tabular}

${ }^{y}$ Data in columns are the averages of two experiments.

${ }^{\mathrm{z}}$ Values in columns followed by the same letter are not significantly different according to an LSD test at $\alpha=0.05$. 
sults of this study indicate that spore germination, germ tube elongation, and mycelium growth of $B$. dothidea increased as $\psi$ decreased from 0 to $-2.0 \mathrm{MPa}$ and declined as $\psi$ further decreased. Increased radial growth of mycelium as a result of slightly decreasing $\psi$ of conventional media has also been reported in other fungi $(1,3,5,10,11,13,26,31)$. The optimal $\psi$ for growth of fungi depends on the species as well as the osmotic medium, temperature, and other environmental factors (6). Our data indicate that the optimum range of $\psi$ for growth of $B$. dothidea on PDA was -1 to $-2 \mathrm{MPa}$. Growth enhancement may result from uptake of solute, which may lower $\psi$ of the protoplasm to a value more ideal for cellular processes or may increase turgor and hence mycelial growth acceleration (6).

Our results indicate that growth of $B$. dothidea was greater in media when the $\psi$ was adjusted with sucrose rather than with KCl. Similar results were reported for other fungi, such as Monilinia fructicola (11), Macrophomina phaseolina (26), and Phytophthora spp. (31). Using sucrose to control $\psi$ results in higher growth rate of fungi, which was reported to be due principally to sucrose utilization as a carbon and energy source (33). However, the higher growth of $M$. phaseolina in the medium amended with sucrose may also be due to the higher production of polyols by the fungus compared with those in media amended with $\mathrm{KCl}$ or $\mathrm{NaCl}$ (26).

Greenhouse experiments indicated that drought stress was associated with predisposition of pistachio to infection by $B$. dothidea. This is in agreement with previously published reports on other hosts, although in our greenhouse study a different inoculation method was used. In our study, pistachio leaves were inoculated with a spore suspension, whereas in other studies plant stems were inoculated with mycelium plugs $(7,14,15,27)$. In our study, the 2-year-old pistachio trees were more prone to water stress and showed more irreversible wilt than the 1-year-old trees, probably because older trees consume more water than younger trees. Severe water stress has been reported to increase disease caused by $B$. dothidea in other hosts, such as apple (12), sweetgum (25), European white birch (7), and peach (27). Similar results have been described for other plant-pathogenic fungi. For example, larger cankers were induced by Lasiodiplodia theobromae on water-stressed dogwood (Cornus florida L.) (24), by Hypoxylon prunatum on water-stressed Populus tremuloides (2), and by Septoria musiva on water-stressed hybrid poplar clones (16). However, opposite responses (smaller cankers) have also been reported, such as in water-stressed honeylocust trees (Gleditsia triacanthos L.) inoculated with Thyronectria austro-americana (14). Thus, the effect of water stress on disease development may depend on the type of pathogenhost system under analysis.

Laboratory tests agree and support the greenhouse experiments in this study. The $\psi$ of mature pistachio leaves was -0.485 $\mathrm{MPa}$ in trees without water stress and $-0.75 \mathrm{MPa}$ in trees with 11 days of waterstress in 1999 (Table 3). The laboratory experimental data indicated that $B$. dothidea grew rapidly as $\psi$ decreased from 0 to $-2 \mathrm{MPa}$. Thus, the pathogen might grow more rapidly in leaves with $\psi=-0.75 \mathrm{MPa}$ (water stress) than $\psi=-0.485 \mathrm{MPa}$ (without water stress), which may explain partially why drought stress increased Botryosphaeria blight on pistachio leaves. This is also in agreement with field observations of increased Botryosphaeria blight outbreaks and spread of the disease during and after prolonged drought conditions in California during 1990 to 1995 . Water stress may cause many complex changes in plant

Table 3. Effects of drought stress on Botryosphaeria blight of pistachio caused by Botryosphaeria dothidea in a greenhouse

\begin{tabular}{lccc}
\hline Year/experiment & $\begin{array}{c}\text { Days without } \\
\text { water }\end{array}$ & $\begin{array}{c}\text { Water potential }(\psi) \\
\text { of mature leaves }(-M P a)\end{array}$ & Disease index $^{\mathbf{w}}$ \\
\hline 1999 / I and II & 0 & $0.485^{\mathrm{x}} \mathrm{c}^{\mathrm{y}}$ & $0.530^{\mathrm{x}} \mathrm{c}^{\mathrm{y}}$ \\
& 5 & $0.554 \mathrm{bc}$ & $1.070 \mathrm{~b}$ \\
& 8 & $0.635 \mathrm{~b}$ & $1.350 \mathrm{ab}$ \\
$2000 / \mathrm{I}$ & 11 & $0.750 \mathrm{a}$ & $1.600 \mathrm{a}$ \\
& 0 & $0.472^{\mathrm{z}} \mathrm{d}$ & $0.551^{\mathrm{z}} \mathrm{c}$ \\
& 5 & $0.576 \mathrm{c}$ & $0.692 \mathrm{bc}$ \\
$2000 / \mathrm{II}$ & 8 & $0.702 \mathrm{~b}$ & $0.746 \mathrm{~b}$ \\
& 11 & $0.868 \mathrm{a}$ & $0.995 \mathrm{a}$ \\
& 0 & $0.466^{\mathrm{z}} \mathrm{c}$ & $0.417^{\mathrm{z}} \mathrm{a}$ \\
& 5 & $0.524 \mathrm{~b}$ & $0.434 \mathrm{a}$ \\
& 8 & $0.550 \mathrm{~b}$ & $0.466 \mathrm{a}$ \\
& 11 & $0.584 \mathrm{a}$ & $0.510 \mathrm{a}$ \\
\hline
\end{tabular}

${ }^{\text {w }}$ Disease index was calculated using five severity categories ( 0 to 4 ), with $0=$ leaves without lesions and $4=$ lesion area greater than three-fourths of leaf area.

${ }^{x}$ The data presented are the averages of two experiments (five replicate trees per treatment).

y Values in columns for each experiment followed by the same letter are not significantly different according to an LSD test at $\alpha=0.05$.

${ }^{\mathrm{z}}$ Data presented are the averages of five replicate trees per treatment for each 2000 experiment I or II. metabolism. For instance, water stress can affect cell growth, division, cell wall synthesis, and plant hormonal balance, and these changes in turn may affect plant resistance to diseases (29). Thus, increased predisposition to Botryosphaeria blight in pistachio under water stress may result from lowered disease resistance of the host plant and/or faster growth of $B$. dothidea in water-stressed pistachio leaves.

In summary, artificially induced drought stress was identified as a major predisposing factor of pistachio to infection by $B$. dothidea. This is the first study of drought stress affecting pistachio Botryosphaeria blight, which may be important in practice. Due to droughts and increased competition for water in California, many pistachio growers face restricted water supplies (9), and controlled-deficit irrigation (reducing irrigation during mid-May through early July) is presently recommended for pistachio (18). Because our results indicated that drought stress could increase Botryosphaeria blight disease, pistachio growers should avoid drought stressing their pistachio trees if they observe Botryosphaeria blight in their orchards.

\section{ACKNOWLEDGMENTS}

We thank the California Pistachio Commission for funding of this research. We are grateful to Yong Luo for comments on this manuscript and his helpful suggestions.

\section{LITERATURE CITED}

1. Alderman, S. C., and Lacy, M. L. 1984. Influence of temperature and moisture on growth and sporulation of Botrytis squamosa. Can. J. Bot. 62:2793-2797.

2. Bagga, D. K., and Smalley, E. B. 1969. Factors affecting canker development on Populus tremuloides artificially inoculated with $\mathrm{Hy}$ poxylon prunatum. Can. J. Bot. 47:907-204.

3. Brownell, K. H., and Schneider, R. W. 1985. Roles of matric and osmotic components of water potential and their interaction with temperature in the growth of Fusarium oxysporum in synthetic media and soil. Phytopathology 75:53-57.

4. California Pistachio Commission. 2000. California pistachio 1999 acreage and crop value. Pages 68-69 in: California Pistachio Industry Annual Report 1999-2000.

5. Cook, R. J. 1981. Water relations in the biology of Fusarium. Pages 236-244 in: Fusarium: Disease, Biology, and Taxonomy. P. E Nelson, T. A. Tousoun, and R. J. Cook, eds. Pennsylvania State University, University Park.

6. Cook, R. J., and Duniway, J. M. 1981. Water relations in the life cycles of soilborne plant pathogens. Pages 119-151 in: Water Potential Relation in Soil Microbiology. J. F. Par, W. R. Gardner, and L. F. Elliot, eds. Soil Society of America Special Publ. No. 9.

7. Crist, C. R., and Schoeneweiss, D. F. 1975. The influence of controlled stresses on susceptibility of European white birch stems to attack by Botryosphaeria dothidea. Phytopathology 65:369-373.

8. Eamus, D., and Jennings, D. H. 1985. Water, turgor and osmotic potentials of fungi. Pages 27-48 in: Water, Fungi and Plants. P. G. Ayres and L. Boddy, eds. Cambridge University Press, London.

9. Goldhamer, D. A., Beede, R., Fusi, S., and Van Brocklin, F. 1992. Controlled deficit irri- 
gation timing on pistachio tree productivity. Pages 74-79 in: California Pistachio Industry Annual Report 1991-1992.

10. Grogan, R. G., and Abawi, G. S. 1975. Influence of water potential on growth and survival of Whetzelinia sclerotiorum. Phytopathology 65:122-138.

11. Hong, C., and Michailides, T. J. 1999. Mycelial growth, sporulation, and survival of Monilinia fructicola in relation to osmotic potential and temperature. Mycologia 95:871876.

12. Hutton, K. E. 1958. Dothiorella canker and dieback of apple trees. Agric. Gaz. N.S.W. 69:192-225.

13. Imolehin, E. D., Grogan, R. G., and Duniway, J. M. 1980. Effect of temperature and moisture tension on growth, sclerotial production, germination, and infection by Sclerotinia minor. Phytopathology 70:1153-1157.

14. Jacobi, W. R., and Riffle, J. W. 1989. Effects of water stress on Thyronectria canker of honeylocusts. Phytopathology 79:1333-1337.

15. Madar, Z., Solel, Z., and Kimchi, M. 1989. Effects of water stress in cypress on the development of cankers caused by Diplodia pinea $\mathrm{f}$. sp. cupressi and Seiridium cardinale. Plant Dis. 73:484-486.

16. Maxwell, D. L., Kruger, E. L., and Stanosz, G. R. 1997. Effects of water stress on colonization of poplar stems and excised leaf disks by Septoria musiva. Phytopathology 87:381-388.

17. Michailides, T. J. 1991. Pathogenicity, distribution, sources of inoculum, and infection courts of Botryosphaeria dothidea on pistachio. Phytopathology 81:566-573.

18. Michailides, T. J., and Morgan, D. P. 1992. Effects of temperature and wetness duration on infection of pistachio by Botryosphaeria dothidea and management of disease by reducing duration of irrigation. Phytopathology 82:1399-1406.

19. Michailides, T. J., and Morgan, D. P. 1993. Spore release by Botryosphaeria dothidea in pistachio orchards and disease control by altering the trajectory angle of sprinklers. Phytopathology 83:145-152.

20. Michailides, T. J., Morgan, D. P., Felts, D., Krueger, W., and Weinberger, G. 2000. Chemical control of Botryosphaeria blight of pistachio in California. Pages 123-124 in: California Pistachio Industry Annual Report 1999-2000.

21. Michailides, T. J., Morgan, D. P., Felts, D., and Ribiero, B. 1997. Disease monitoring, prediction and spread of Botryosphaeria dothidea in central California pistachio orchards. Pages 73-81 in: California Pistachio Industry Annual Report 1996-1997.

22. Michailides, T. J., Morgan, D. P., and Sullivan, A. 1996. Spread of Botryosphaeria dothidea in pistachio orchards of the San Joaquin Valley. Pages 123-128 in: California Pistachio Industry Annual Report 1995-1996.

23. Michailides, T. J., Teviotdale, B. L., and Weinberger, G. 1999. Botryosphaeria panicle and shoot blight management program for California pistachios. Pages 1-3 in: Botryosphaeria Blight of Pistachio: Identification and Control Manual, California Pistachio Commission, Fresno.

24. Mullen, J. M., Gilliam, C. H., Hagan, A. K., and Morgan-Jones, G. 1991. Canker of dogwood caused by Lasiodiplodia theobromae, a disease influenced by drought stress or cultivar selection. Plant Dis. 75:886-889.
25. Neely, D. 1968. Bleeding necrosis of sweetgum in Illinois and Indiana. Plant Dis. Rep. 52:223-225.

26. Olaya, G., and Abawi, G. S. 1996. Effect of water potential on mycelial growth and on production and germination of sclerotia of Macrophomina phaseolina. Plant Dis. 80:1347-1350.

27. Pusey, P. L. 1989. Influence of water stress on susceptibility of nonwounded peach bark to Botryosphaeria dothidea. Plant Dis. 73:10001003.

28. Robinson, R. A., and Stokes, T. H. 1959. Electrolyte Solutions, the Measurement and Interpretation of Conductance, Chemical Potential, and Diffusion in Solution of Simple Electrolytes. 2nd ed. Butterworths, London.

29. Schoeneweiss, D. F. 1981. The role of environmental stress in diseases of woody plants. Plant Dis. 65:308-314.

30. Schoeneweiss, D. F. 1986. Water stress predisposition to disease-an overview. Pages 157-175 in: Water, Fungi and Plants. P. G. Ayres and L. Boddy, eds. Cambridge University Press, London.

31. Sommers, L. E., Harris, R. F., Dalton, F. N. and Gardner, W. R. 1970. Water potential relations of three root-infecting Phytophthora species. Phytopathology 60:932-934.

32. Whiting, E. C., and Rizzo, D. M. 1999. Effect of water potential on radial growth of Armil laria mellea and $A$. gallica isolates in culture. Mycologia 91:627-635.

33. Woods, D. M., and Duniway, J. M. 1986 Some effects of water potential on growth, turgor, and respiration of Phytophthora cryp togea and Fusarium moniliforme. Phytopathology $76: 1248-1254$ 